\title{
Sudden death due to isolated adrenal tuberculosis
}

\author{
S. Ward \& C.C. Evans
}

Royal Liverpool Hospital, Prescot Street, Liverpool L7 8XP, UK.

\begin{abstract}
Summary: A 65 year old man admitted to hospital for investigation of pleural thickening was found to have carcinoma of the prostate with metastases. Before investigations were completed the patient collapsed unexpectedly with hypotension. A post mortem examination revealed tuberculosis of both adrenal glands without evidence of tuberculosis in any other organ.
\end{abstract}

\section{Introduction}

The incidence of pulmonary tuberculosis is declining but that of non-pulmonary disease remains constant (Ananko \& Burska, 1981). Unusual forms are particularly likely to occur in the elderly and immigrant populations. We wish to report a case of isolated adrenal tuberculosis causing sudden death in a 65 year old Caucasian male, which remained undiagnosed until necropsy.

\section{Case report}

A 65 year old Caucasian male was admitted to hospital for investigation of pleural thickening. Thirty months previously a laryngeal biopsy which was performed for hoarseness, had shown non-caseating epithelioid granulomata. A repeat biopsy 6 months later revealed normal histology and Ziel-Nielsen stain with samples sent for tuberculosis (TB) culture were negative. Chest radiographs had been performed at 3 monthly intervals and the last of these had shown the pleural thickening. He had lost nearly $16 \mathrm{~kg}$ in weight during the preceding year but was otherwise asymptomatic. On examination he appeared very well, was apyrexial, had no lymphadenopathy, but a circinate violaceous rash was found on the inner aspect of both thighs. The blood pressure was $140 / 90 \mathrm{~mm} \mathrm{Hg}$ and his chest was clear, with normal skin pigmentation. The liver was enlarged to $3 \mathrm{~cm}$ below the costal margin, and an enlarged prostate could be felt on rectal examination. Radiography revealed pleural thickening and a dense ninth thoracic vertebra. Further investigations showed elevated acid phosphatase of $19 \mathrm{IU} / 1$, urea $5.0 \mathrm{mmol} / 1$, sodium $140 \mathrm{mmol} / 1$, potassium $4.5 \mathrm{mmol} /$ 1 , calcium $2.2 \mathrm{mmol} / 1$, albumin $38 \mathrm{~g} / 1$, phosphate $1.0 \mathrm{mmol} / 1$, normal immunoglobulins, normal liver

Correspondence: S. Ward, M.B., M.R.C.P.

Accepted: 8 November 1984 function tests, haemoglobin $13.5 \mathrm{~g} / \mathrm{dl}$, white cell count $10 \times 10^{9} / 1$, with normal differential and an elevated erythrocyte sedimentation rate of $70 \mathrm{~mm} / \mathrm{h}$.

A radioisotope bone scan indicated multiple hot spots throughout the skeleton. A skin biopsy of the rash showed non-caseating epithelioid granulomata, with negative Ziel-Nielsen stain and TB culture. A Mantoux test proved positive at dilution $1 / 10,000$ and an ultrasound scan of the liver and pulmonary function tests were normal. A prostatic biopsy confirmed the suspicion of carcinoma of the prostate.

These findings led to a diagnosis of probable skin sarcoid and disseminated carcinoma of the prostate. The day before subcapsular orchidectomy he collapsed with a blood pressure of $80 / 50 \mathrm{mmHg}$, sinus tachycardia and no other electrocardiographic abnormality. The patient died $3 \mathrm{~h}$ later from a presumed pulmonary embolus. A post mortem examination revealed fibrous pleural thickening, carcinoma of the prostate with bony metastases and, most unexpectedly, the complete replacement of the adrenal glands by caseous material containing many acid-fast bacilli. There was no evidence of tuberculosis in any other organ.

\section{Discussion}

Isolated adrenal tuberculosis is extremely rare and a previous study showed only one such case, out of 370 reports of non-pulmonary tuberculosis, within a $10 \mathrm{y}$ period (Edlin, 1978). In common with this case the detection of tuberculosis in unusual sites is difficult, and frequently the diagnosis is made only at necropsy (Snider, 1975). The patient's non-specific complaints were attributed to the prostatic carcinoma but vague symptoms and signs such as low grade pyrexia, general malaise, and weight loss, are the usual presenting features of non-pulmonary tuberculosis (Lane, 1982). 
Occasionally more specific signs and symptoms point directly to the organ involved, although the abnormality may not be attributed to tuberculosis. In this patient, normal blood pressure, lack of skin pigmentation, and normal electrolytes at presentation with subsequent sudden collapse are unusual considering the adrenals were completely necrotic. The unusual skin lesions may have represented an epithelioid

\section{References}

ANANKO, J. \& BURSKA, I. (1981). Diagnostic and legal aspects of clinically unrecognised adrenal tuberculosis. Wiadomości Lekarskie, 34, 1393.

EDLIN, G.P. (1978). Active tuberculosis unrecognised until necropsy. Lancet, i, 650. reaction to the tuberculosis; tubercle bacilli were not isolated from these lesions.

Isolated non-pulmonary tuberculosis occurs in unusual sites and should be considered in differential diagnosis, since it is a readily treatable condition. Acute adrenal collapse is also treatable and patients should not die with unexplained hypotension without receiving intravenous hydrocortisone.

LANE, D.J. (1982). Extrapulmonary tuberculosis. Medicine International, 1, 983.

SNIDER, D.E.JR. (1975). Extrapulmonary tuberculosis in Oklahoma, 1965-73. American Review of Respiratory Diseases, 111, 641. 